\title{
CRITERIA FOR THE VULNERABILITY ANALYSIS OF STRUCTURAL AGGREGATES IN HISTORICAL CENTERS
}

\author{
S. TONNA ${ }^{1}$, M. BORIANI ${ }^{2}$, M. C. GIAMBRUNO ${ }^{3}$, C. $^{\text {CHESI }}{ }^{4}$ \\ ${ }^{1}$ Politecnico di Milano - DAStU Department \\ Piazza Leonardo da Vinci, 32 - 20133 Milano, Italy \\ e-mail: sandra.tonna@polimi.it (*corresponding author) \\ ${ }^{2}$ Politecnico di Milano - DAStU Department \\ Piazza Leonardo da Vinci, 32 - 20133 Milano, Italy \\ e-mail: maurizio.boriani@polimi.it \\ ${ }^{3}$ Politecnico di Milano - DAStU Department \\ Piazza Leonardo da Vinci, 32 - 20133 Milano, Italy \\ e-mail: mariacristina.giambruno@polimi.it \\ ${ }^{4}$ Politecnico di Milano- A.B.C. Department \\ Piazza Leonardo da Vinci, 32 - 20133 Milano, Italy \\ e-mail: claudio.chesi@polimi.it
}

Keywords: Aggregate, historical center, seismic vulnerability, on-site survey

\begin{abstract}
The need to define earthquake prevention and intervention strategies, in order to limit dramatic consequences for the society, has acquired a high priority in countries where, like in Italy, a large number of historic masonry buildings (listed or not) are located in areas with medium to high seismic hazard. From the point of view of the level of safety to be reached through interventions, the concept of improvement, as opposed to that of full strengthening, is nowadays widely accepted in the case of monumental heritage; what is still lacking, in many cases, is a procedure for the vulnerability analysis, as a synthetic evaluation tool for the definition of intervention priorities. In a modern perspective, where territorial planning is conceived as a safety project for the territory, the seismic vulnerability analysis should not be confined to specific technical documents, but should rather be considered at a general level; in this way only, indeed, the issue of seismic risk could acquire widespread knowledge and awareness in the population, also pushing urban planning in the direction of general programs for the increase of seismic safety. In the above perspective, revised criteria have to be developed for a global vulnerability assessment, to be introduced at a general level in territorial planning. Considering that seismic vulnerability analyses are strictly dependent on specific building typologies, attention has been focused, in the present study, on to the case of structural aggregates in historical centers, thus following the needs of the Italian Civil Protection Agency in relation to seismic prevention activities in historical towns. The research, which is still in progress, takes advantage from the application to a few study cases, suitable for the experimental testing of procedures.
\end{abstract}




\section{INTRODUCTION}

The frequent recurrence of seismic events in Italy in recent times has stressed the need, for the society, to develop effective levels of preparedness, in order to reduce the negative impact on the safety of people, the conservation of the built environment, and the continuity of normal life. To this purpose, the seismic vulnerability analysis of buildings and public works in general is a fundamental prevention tool; within this context, vulnerability has to be intended in its original meaning, i.e., a fast qualitative evaluation of the inclination, for the structure, to suffer damage from an earthquake. Based on meaningful indicators, not necessarily of a structural nature, the vulnerability analysis is therefore suitable for being applied to large groups of buildings with a statistical purpose.

Originally, vulnerability analyses were conceived in view of risk reduction strategies with the purpose of highlighting the possible lack of seismic resistance, thus suggesting consolidation interventions and favouring seismic damage prevention. In recent times, as a consequence of the development of effective and well organized Civil Protection Services for natural disasters and, in particular, earthquakes, vulnerability analyses have also been recognized as the necessary tool for a positive management of emergency situations, in the sense of supporting preparedness to damage scenarios.

Starting from the traditional approach to vulnerability evaluations, based on the analysis of single structural units, new procedures have now to be formulated, extending consideration to entire structural aggregates, in view of the development of wide damage scenarios at the urban scale. Recently, this specific need has been formulated by the Italian Civil Protection
Agency as a support to the development of Civil Protection plans; specifically, in accordance
with the typical nature of the Italian buil environment, the study is focused on the
vulnerability analysis of historical aggregates of ancient urban centers (Fig) 1). for free at https//www.scipedia.com to download the version without the watermark
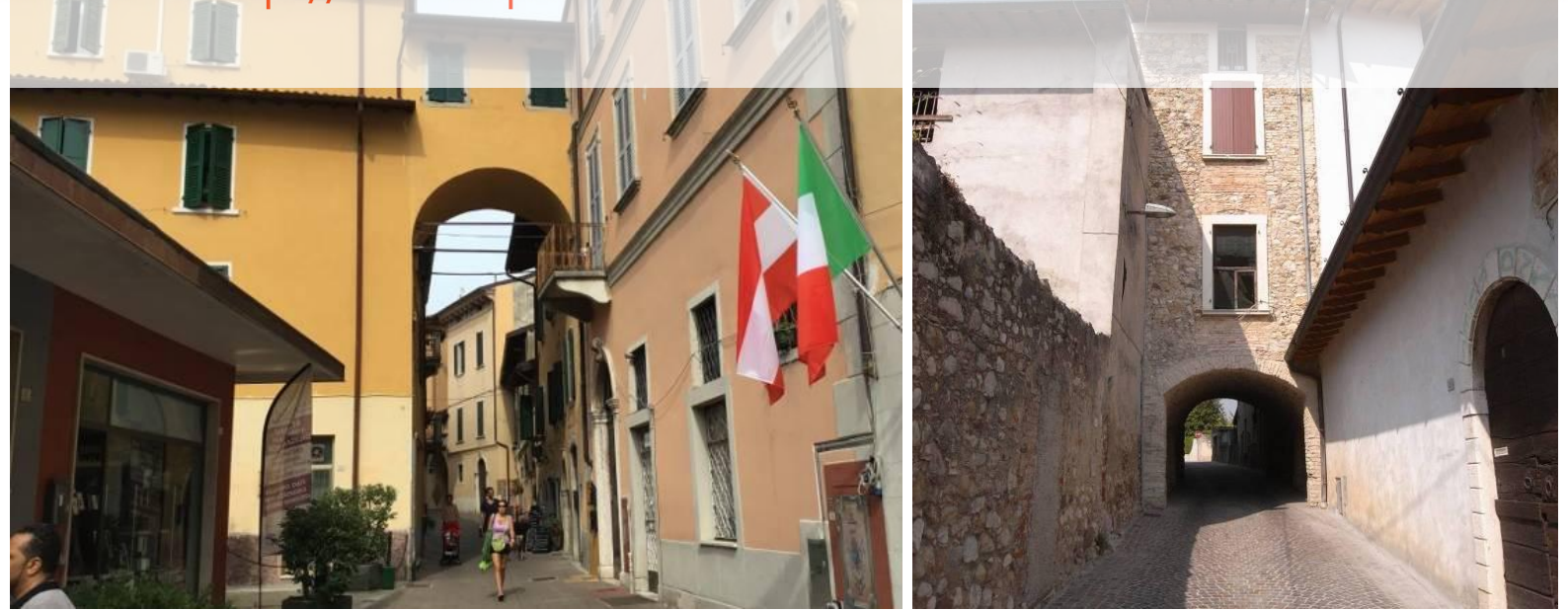

Figure1: Typical views of historical aggregates.

The paper presents the criteria adopted for the re-formulation of traditional vulnerability analyses at the scale of aggregates of structural units, in the spirit of a qualitative analysis for 
a fast application at a wide scale, taking advantage of the numerous studies on seismic vulnerability procedures which have been developed through time.

\section{THEMATIC FRAMEWORK}

The vulnerability analysis, as originally conceived [1], clearly showed the possibility of developing the formal implementation of a qualitative approach to the analysis of the seismic capacity of masonry buildings. This was supported by the high degree of knowledge which had been reached in relation to the seismic performance of masonry buildings, as a result of the repeated post earthquake field surveys documenting typical damage modalities, followed by analytical interpretations. Specifically, vulnerability analyses focused on the occurrence of the structural details which have been generally recognized in favour of the positive performance of a masonry building under the effect of seismic actions; typically, wall-to-wall connections, diaphragmatic behaviour of floor slabs, shear resistance of masonry piers, etc [1, $2,3]$.

At present, in consideration of the remarkable growth of experience in this field in recent times, qualitative approaches to the evaluation of masonry structures are even more justified $[4,5,6,7]$. In addition to vulnerability analyses, indeed, similar procedures have been developed in relation to other needs. Meaningful examples are given by the special form which is normally used in Italy for the evaluation of buildings after a seismic event in terms of the possibility of safe access and usage, and by the procedure for the definition of seismic risk classes for residenti

It is also of interest assessment of seismid only, but can be exten and, through an experience details and structural behaviour.
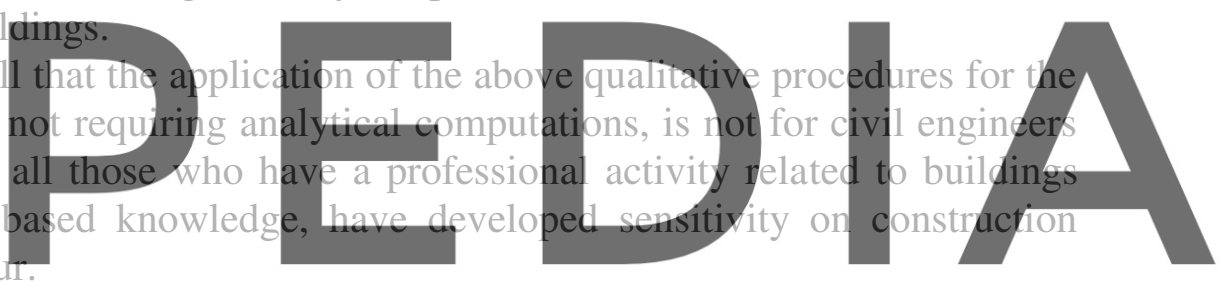

Vulnerability analyses were originally based on the field inspection of single structural

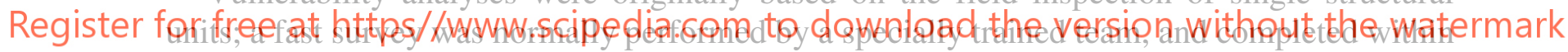
a few hours, filling in a form and evaluating, as a final result, the vulnerability index.

Extending such procedure to the case of aggregates, still preserving the nature of a fast qualitative evaluation, new meaningful parameters have to be identified for a correct interpretation of the structural behaviour. Also, it has to be considered that the vulnerability analysis, in this case, is mainly addressed to the needs of Civil Protection plans and, therefore, the identification of situations involving high danger levels.

Looking at typical aspects characterizing the seismic response, attention has to be focused primarily onto structural regularity, degree of connection of the different units, and possible transformations occurred through time, which may have altered the original structural layout. All this has to be recognized through a simple visual inspection of the different fronts of the aggregate.

More in detail, the issue of plan and elevation irregularities now corresponds to a generally acquired concept, normally addressed also by building codes. It has to be considered that both irregularity forms may be enhanced in the case of an aggregate, thus assuming a special relevance in terms of potential damage. Similarly, the degree of connection of different parts, which has normally to do with the connection of wall panels and floor slabs within a single 
building, has to be extended to the scale of the aggregate in terms of interaction of the different structural units.

Finally, having to do with historical aggregates, modifications of the original resisting system may have been introduced due to changes in the usage conditions of the building; in some cases such modifications may have seriously compromised the lateral strength of the building.

The above considerations clearly show that a qualitative approach to the evaluation of the seismic vulnerability of an aggregate is meaningful and, probably, should be always considered before developing accurate models for the analysis of single structural units. The original concept of a vulnerability analysis, therefore, is totally justified also in the case of aggregates in relation to the present needs of analysing seismic safety.

\section{URBAN-LEVEL VULNERABILITY ANALYSIS}

Several research works $[3,8,9,10]$ have been addressed to the analysis of seismic vulnerability in historical centers, showing a wide variety in the methodological trends. All the analyzed methods can be classified on the basis of a single criterion according to the assumptions done for the investigation scale and the analytical approach. Following the classification proposed by $[10,11]$, the various methodologies can be organized, from the point of view of the analysis scale, into three macro-groups (urban, district, building) and each of these can be further organized into sub-categories, in relation to the method of analysis (direct, indirect

For the research in provides a methodolog less connected structural addressed to the methoc homogeneous group of buildings, which is t, conventionat and hylorid) $[12,13,14$,
progress, the post appropriate reference
y for a global yiev of a stratified urban
ral aggregates. Among the different
dologies defined as "indirect" and "hybridur.
f buildings, which is globally assigned

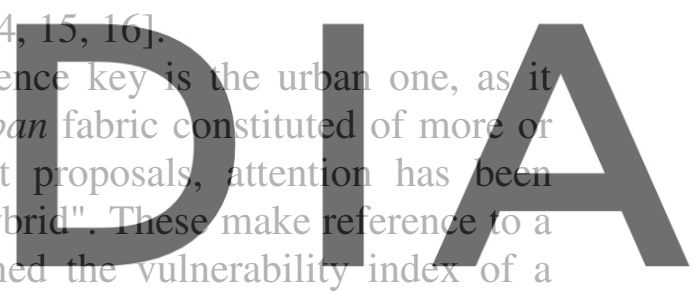
model case, which was analyzed through an in-depth study. Such methods are both derived

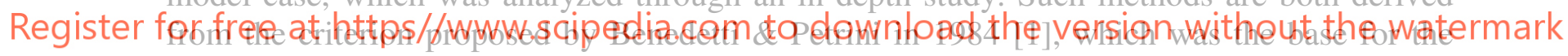
formulation of the first and second level vulnerability analyses. It is still in use at the international level and has inspired all the other methodologies for vulnerability analysis which were introduced subsequently.

In the various alternatives, modifications to the original method concerned both the scale (from building to aggregate), and the methodology for the choice of the pilot case. Recently, indeed, an opposite approach has been introduced: following a general investigation of the whole urban center, the most representative case studies are selected for a second phase indepth research $[5,6,12]$.

Finally, to the purpose of a really effective vulnerability analysis, a critical issue is given by the choice of the evaluation parameters and the definition of the relative weighting coefficients. In the original formulation by Benedetti \& Petrini [1] eleven parameters were defined; among these, only one was based on a numerical evaluation (item 3 in Table 1), two accounted for general aspects (items 10 and 11 in Table 1), while the remaining eight parameters were based on a qualitative evaluation of structural aspects. In recent works [8, 11] the number of the parameters has increased to 14 [8] or 15 [11], in order to take into 
account stratifications occurred with time and interactions among structural units within the aggregate.

Tables 1, 2, and 3 show details about the different procedures developed by Benedetti \& Petrini in 1984 [1], Vincente in 2011 [8], and Ferreira in 2017 [11], respectively.

Methodologies present differences in the selection and ordering of the vulnerability parameters and in the relative weighting coefficients, whereas all of them make reference to four vulnerability classes (A-B-C-D) for the evaluation of each single parameter.

Table 1: Items considered in the Benedetti \& Petrini, vulnerability index method [1]

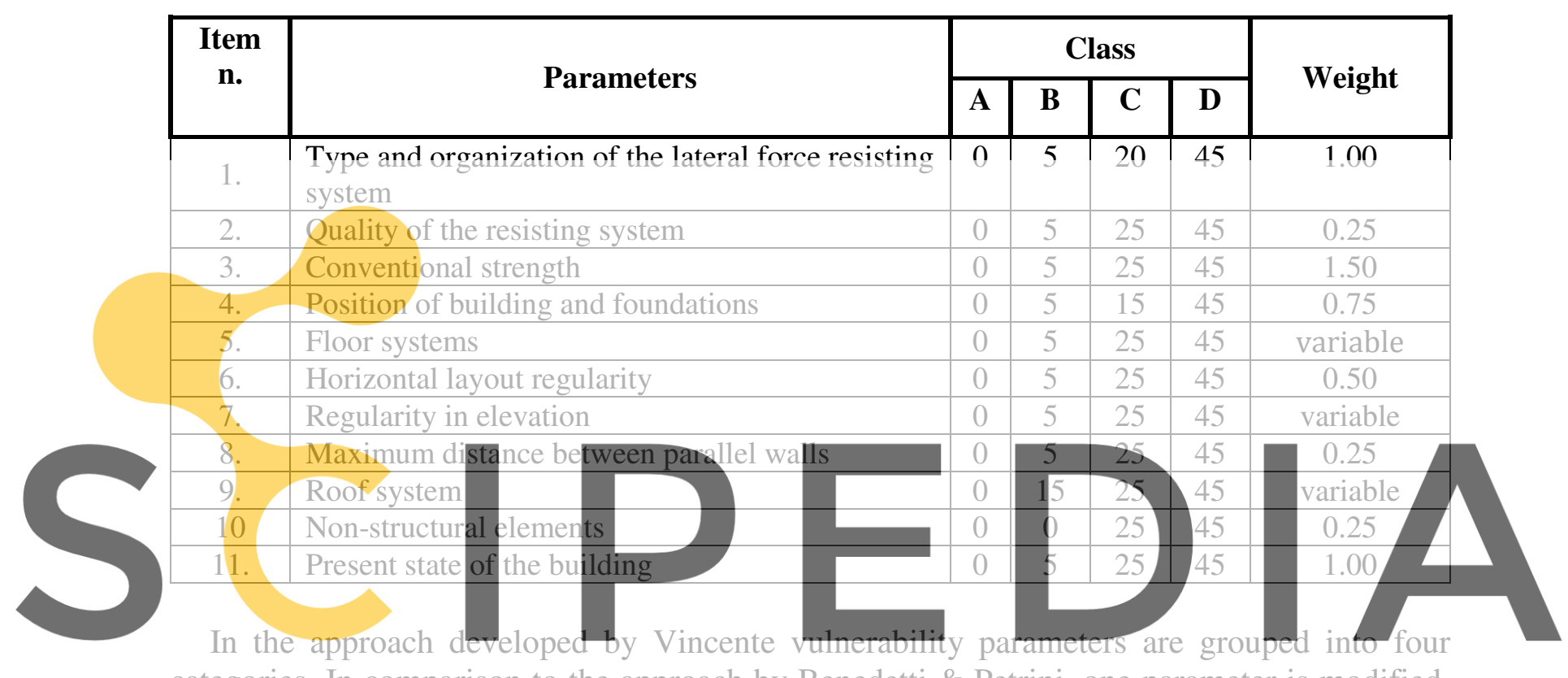

categories. In comparison to the approach by Benedetti \& Petrini, one parameter is modified,

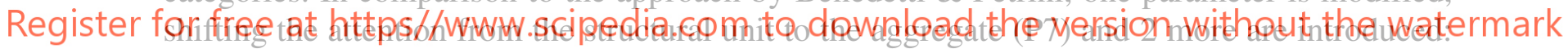
opening alignment on the facade (P10) and aggregate fragilities (P13).

As far as vulnerability classes (A-B-C-D) are concerned, they are associated to similar scores, with the only differences in class $\mathrm{C}$, where the value is decreased to 20 , and class $\mathrm{D}$, where it is increased to 50. Weighting coefficients also present differences, being always associated to fixed values.

Ferreira, like Benedetti \& Petrini, makes reference to individual parameters, without grouping them into categories. The vulnerability analysis of the aggregate is based on fifteen parameters, considering also structural stratifications and the presence of typological or structural heterogeneities between adjacent buildings (item n. 14). Modifications in the vulnerability classes are also present, due to the introduction of negative values for parameters $11,12,14$, and 15; fixed values are used for weighting coefficients.

Through a quick comparison of the above procedures, differences can be easily identified: vulnerability analysis, initially addressed to a single structural unit, is then extended to a structural aggregate and, consequently, the choice of parameters is different. Moreover, while the original method was based on a field survey of the building to be performed from both 
outside and inside, the other two are more concentrated on the external survey of the building; in addition, they are structured in order to allow for an easier final calculation.

Table 2: Items considered in the Vincente, vulnerability index method [8]

\begin{tabular}{|c|c|c|c|c|c|c|}
\hline \multirow{2}{*}{$\begin{array}{c}\text { Item } \\
\text { n. }\end{array}$} & \multirow{2}{*}{ Categories and Parameters } & \multicolumn{4}{|c|}{ Class } & \multirow{2}{*}{ Weight } \\
\hline & & $\mathbf{A}$ & $\mathbf{B}$ & $\mathbf{C}$ & $\mathbf{D}$ & \\
\hline \multirow[t]{7}{*}{1.} & Structural building system & & & & & \\
\hline & P1. Type of the resisting system & 0 & 5 & 20 & 50 & 0.75 \\
\hline & P2. Quality of the resisting system & 0 & 5 & 20 & 50 & 1 \\
\hline & P3. Conventional strength & 0 & 5 & 20 & 50 & 1.50 \\
\hline & P4. Maximum distance between walls & 0 & 5 & 20 & 50 & 0.50 \\
\hline & P5. Number of floors & 0 & 5 & 20 & 50 & 1.50 \\
\hline & P6. Location and soil conditions & 0 & 5 & 20 & 50 & 0.75 \\
\hline \multirow[t]{6}{*}{2.} & Irregularities and interactions & & & & & \\
\hline & P7. Aggregate position and interactions & 0 & 5 & 20 & 50 & 1.50 \\
\hline & P8. Plan configuration & 0 & 5 & 20 & 50 & 0.75 \\
\hline & P.9 Regularity in height & 0 & 5 & 20 & 50 & 0.75 \\
\hline & P10. Wall facade openings and allignments & 0 & 5 & 20 & 50 & 0.50 \\
\hline & Floor slabs and roof & & & & & \\
\hline \multirow{2}{*}{3.} & P11. Horizontal diaphgrams & 0 & 5 & 20 & 50 & 1.00 \\
\hline & P12. Roofing systems & 0 & 5 & 20 & 50 & 1.00 \\
\hline \multirow[t]{3}{*}{4.} & Conservation status and other elements & & & & & \\
\hline & P13. Fragilities and conservation state & 0 & & 20 & 50 & 1.00 \\
\hline & P14. Non-structural elements & 0 & 5 & 20 & 50 & 0.50 \\
\hline
\end{tabular}

Register for free at https//wwwscipedia.com to download the Vession withoutthe watermark

\begin{tabular}{|c|l|c|c|c|c|c|}
\hline & A & $\mathbb{B}$ & C & D & \\
\hline 1. & Organization of the vertical resisting system & 0 & 5 & 20 & 45 & 1.00 \\
\hline 2. & Type of the vertical resisting system & 0 & 5 & 25 & 45 & 0.25 \\
\hline 3. & Position of building and foundations & 0 & 5 & 25 & 45 & 0.75 \\
\hline 4. & Resistant elements distribution in plan & 0 & 5 & 25 & 45 & 1.50 \\
\hline 5. & Regularity in plan & 0 & 5 & 25 & 45 & 0.50 \\
\hline 6. & Regularity in elevation & 0 & 5 & 20 & 45 & 1.00 \\
\hline 7. & Floor systems & 0 & 5 & 25 & 45 & 0.75 \\
\hline 8. & Roof system & 0 & 15 & 25 & 45 & 0.75 \\
\hline 9. & Details & 0 & 0 & 25 & 45 & 0.25 \\
\hline 10. & Present state of the building & 0 & 5 & 20 & 45 & 1.00 \\
\hline 11. & Altimetric interaction & -20 & 0 & 15 & 45 & 1.00 \\
\hline 12. & Planimetric interaction & -45 & -25 & -15 & 0 & 1.50 \\
\hline 13. & Horizontal layout regularity & 0 & 15 & 25 & 45 & 0.50 \\
\hline 14. & Typological and structural discontinuities & -15 & -10 & 0 & 45 & 1.20 \\
\hline 15. & Percentage difference between full and & -20 & 0 & 25 & 45 & 1.00 \\
\hline & openings in the facade & & & & & \\
\hline
\end{tabular}


In the present research, the proposal of a new method for vulnerability analyses has benefited from all the previous works; in particular, in line with the approach by Vincente [8], the grouping of vulnerability parameters into macro-classes has been adopted, as it allows for a more effective management of on-site surveys, a better organization of data and, globally, a faster procedure. Criteria for the development of the new procedure are illustrated in the following, together with implementation details.

\section{A PROPOSAL FOR A METHODOLOGY BASED ON KNOWLEDGE LEVELS}

Procedures for the evaluation of seismic vulnerability are based on the definition of a set of meaningful parameters, from which a realistic view of the seismic capacity of the structure can be obtained. This is not a purely theoretical process, as the effectiveness of the selected parameters has to be verified on the field through the analysis of selected case studies. Specifically, an iterative multi-step procedure has to be undertaken, with continuous testing and updating of the evaluation process, until a fast, clear and stable procedure is defined, providing as much as possible user independent results.

Such a process has been started within the current research work and is still in progress; it is believed, however, that the implementation of the final version of a data sheet to be systematically used for on-site applications should come soon to an end. The final product, resulting from the iterative process, will reflect the original idea of a two-step procedure, consisting in a first phase dedicated to the collection of meaningful documents, followed by the field inspection criterion for the field
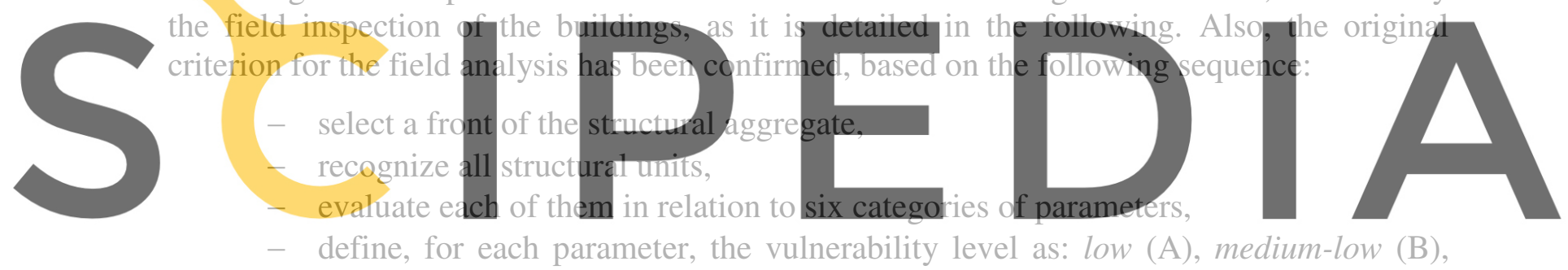

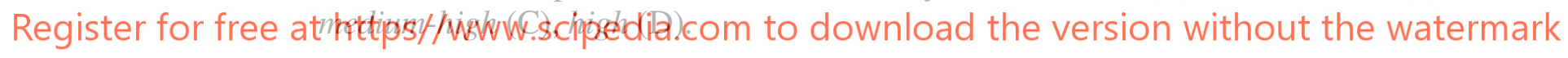

Details about the two-step procedure are discussed in the following. As previously mentioned, this vuinerability analysis is intended for use in the specific case of structurai aggregates in historical centers; masonry, therefore, is the main reference material.

\subsection{Investigation method}

As known, it has become a common practice, well reflected also in building codes, to base the analysis of existing buildings on the acquisition of all the available information, coming to the definition of a specific knowledge level. Normally, information is collected with reference to the building historical analysis, the characterization of structural properties (typology, material, geometry), and action definition.

In the present research it was believed of interest to organize the vulnerability analysis from the point of view of two different knowledge levels: a first one (KL0), consisting in the collection of meaningful documentation from historical archives, municipality offices, and web data (typically, Google Maps), and a second one (KL1), consisting in the field inspection of the aggregate under study. This should be limited, in general, to the external survey of the aggregate fronts but might require, in some cases, a more detailed one to be performed at a 
second time (KL2), based on the internal inspection of buildings and a deeper analysis of the archival documentation.

Clearly, the original formulation of the vulnerability analysis [1] simply consisted in the field survey, while the recognition of different knowledge levels belongs to recent studies and is still under testing [17]. In any case, the added value coming from the analysis of documents marks a meaningful increase in the relevance of vulnerability analysis, also allowing for a lower accuracy level in the field inspection.

Details about the two phases in the knowledge acquisition process are given in the following.

\subsection{Analysis of documents}

The phase defined as KLO is aimed at providing the vulnerability analysis with a minimum knowledge of the building under consideration in view of the on-site survey and the consequent qualitative assessment and classification within vulnerability categories. The parameters to be considered in this phase can all be analyzed in the office through the inspection of several documents, as listed in the following; a major outcome of this analysis would be in the possibility of highlighting the transformations occurred over time through the comparison of the intended use, as noticed in the historical registers, with the current one. Structural transformations may have a remarkable effect on seismic vulnerability; a typical case, frequently occurring, is given by the presence of large openings at the ground floor, which were not present intervention is done consideration of horizon generated.

During this phase, th analysis of the following data and parameters

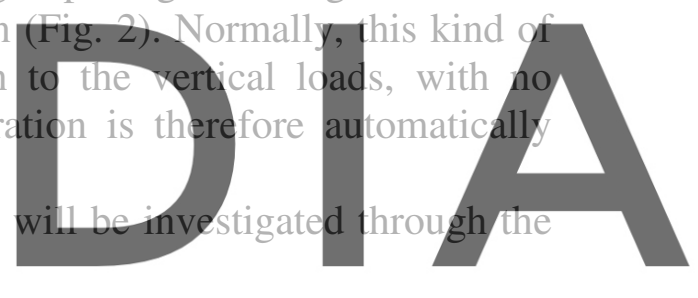

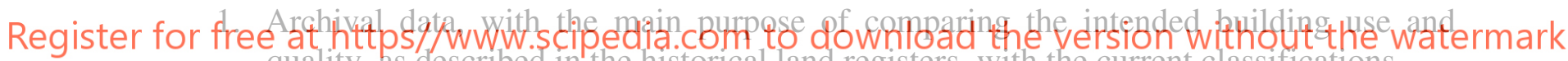
quality, as described in the historical land registers, with the current classifications.

2. Where available, the damage evaluation forms which are normally filled after an earthquake for a first assessment of the building conditions in terms of possible use and restoration needs. In Italy, the "AeDES" form has been developed to this purpose and is normally available in the municipality offices [18].

3. General information at the territorial level, as the urban morphology, its historical development and the topographic profile of the historical center.

4. Ratios between building height and road width and structural connections with neighboring aggregates (Fig. 1).

5. In the presence of a ground slope, the aggregate orientation with respect to the contour lines.

6. The aggregate morphology, namely, regularity in plan, any front offset, or the presence of internal courtyards.

7. The general aggregate conservation status. 


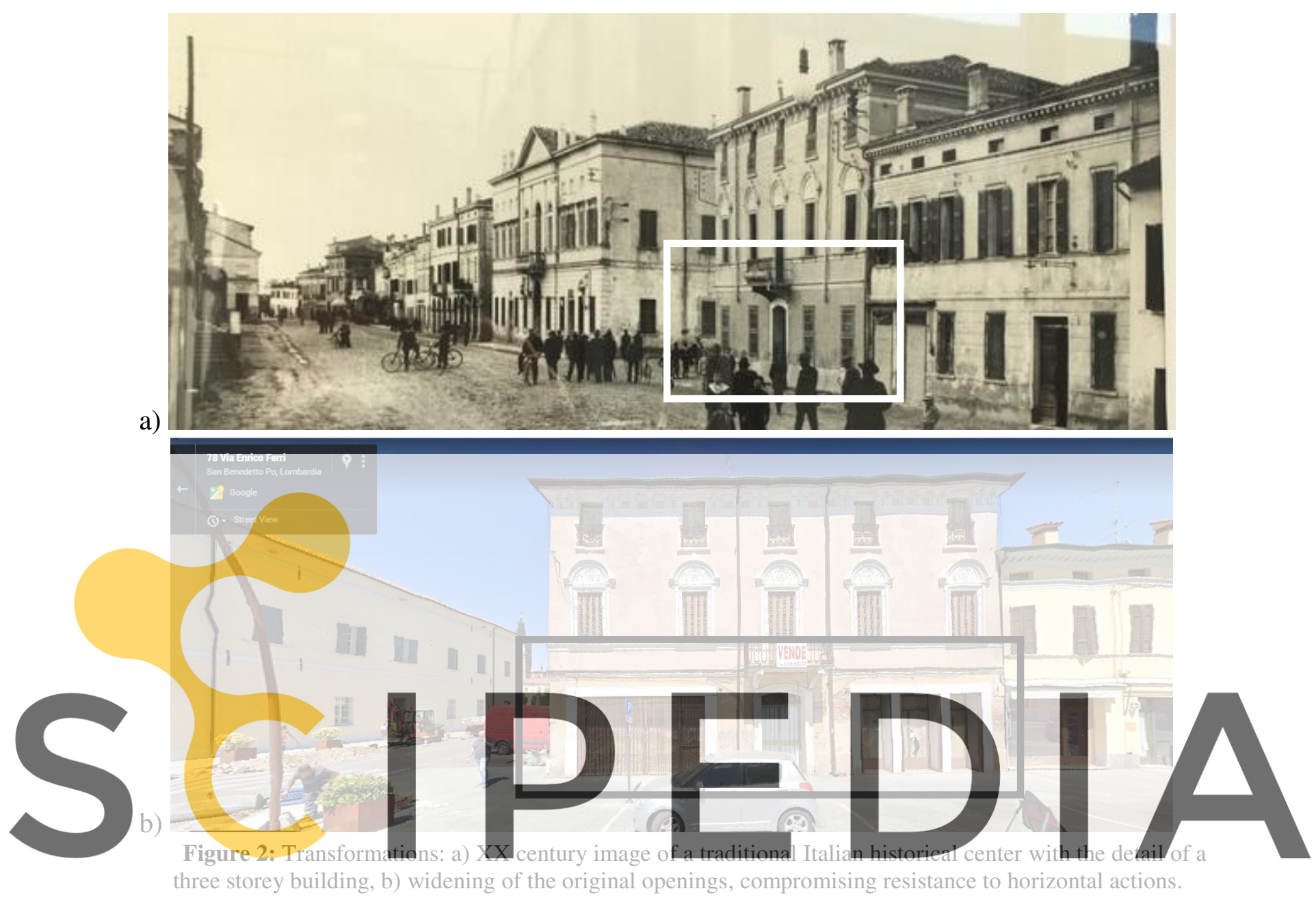

Register for free at https//www.scipedia.com to download the version without the watermark

\subsection{On-site survey}

The next phase, KL1, is based on the analysis of the actual state of the structural aggregate through the qualitative survey of each external front. The main purpose is identifying both structural and architectural characteristics, the current usage conditions and the maintenance state for each facade of the aggregate. This on-site investigation will lead to the achievement of a vulnerability classification for the entire front on the basis of the evaluation of each single structural unit and of its possible interaction with the adjacent ones.

This phase is organized so that the six categories of parameters, as detailed in the following, can be assessed simultaneously for each structural unit of the front under examination:

1. The vertical resisiting system, through the relationship between full and empty spaces and openings alignments. In addition, the presence of openings wider than $2 \mathrm{~m}$ in order to recognize the possible presence of a soft story condition.

2. Fragilities and interactions, through the survey of material inhomogeneity, added portions in elevation, filling of separation joints. 
3. Fragilities in structural units, i.e., the presence of porches, covered walkways, slender elements, large and empty structural units within the aggregate (churches and theatres), chimneys and elements protruding on the road (Figs. 3, 4).

4. The conservation status through all its variants, such as surface degradation, presence of superficial or deep cracks, local collapses.

5. Protruding roof structure, as detectable from the street. The materials and the state of conservation will be indicated.

6. Seismic protection elements belonging to local building techniques, such as buttresses, contrast arches, chains and tie rods, blind arches in the masonry, cantonal, structural joints.

As previously commented, the recourse to a KL2 phase might also be required, in case a deeper knowledge of the building structural conditions is required. This, however, is believed to be a special case,

\subsection{A vulnerability index}

As a result of the two-level evaluation procedure, a number of parameters are assigned to one of the vulnerability classes, A, B, C, or D. In traditional vulnerability analyses, as previously recalled, each vulnerability class is associated to a score to the purpose of performing an easy combination of all the values and coming to the definition of a vulnerability index, expressed as a numeric value within a pre-defined range. This procedure allows for the possibility of specifying weighting coefficients parameters, thus accounting for global vulnerability evaluation. Scores and weighting coefficients will be deft beginning, the choice will be in line with the
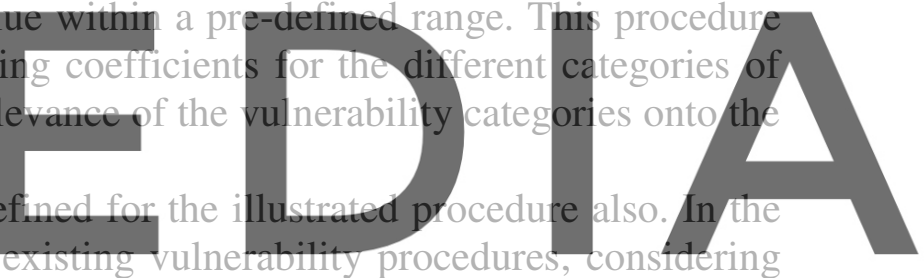

that such values should be based on the results of a wide statistical investigation.

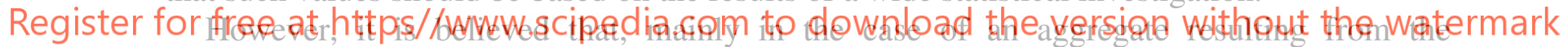

assemblage of several structural units, a single numerical value might not be representative of

the real vulnerability conditions, or even misleading in the case of local critical conditions within a generally sound context. For this reason it has been planned to provide, as the main result of this vulnerability analysis, plant views of the aggregate showing, through colored maps, the distribution of the most critical vulnerability parameters. In this way, local critical situations will be easily recognizable.

\section{CONCLUSIONS}

A renovated interest is present in the research community for seismic vulnerability analyses of buildings, in line with the original meaning of fast qualitative evaluations of the susceptibility to suffer damage from earthquakes. This is due, on the one side, to the need of Civil Protection Services to develop damage scenarios and emergency plans; on the other side, the qualitative approach to the analysis of the seismic performance of masonry buildings has widely improved in recent times.

The continuous progress in earthquake engineering studies, with special reference to the case of existing buildings, is also reflected in the new approach to vulnerability analyses 
through the introduction of different knowledge levels, taking advantage of preliminary information coming from the analysis of archival documentation.

The development of a new procedure for vulnerability analyses, as it has been presented in this work with reference to the special case of structural aggregates in historical centers, has to face still now the problem of defining meaningful numerical values for the different evaluation parameters. The solution to this problem necessarily requires the recourse to a wide statistical campaign. In general, the formulation of a meaningful procedure for seismic vulnerability analyses still remains a complex problem, also in consideration of the need to develop an fast, clear, and stable procedure, suitable for the use by a wide community of technicians.
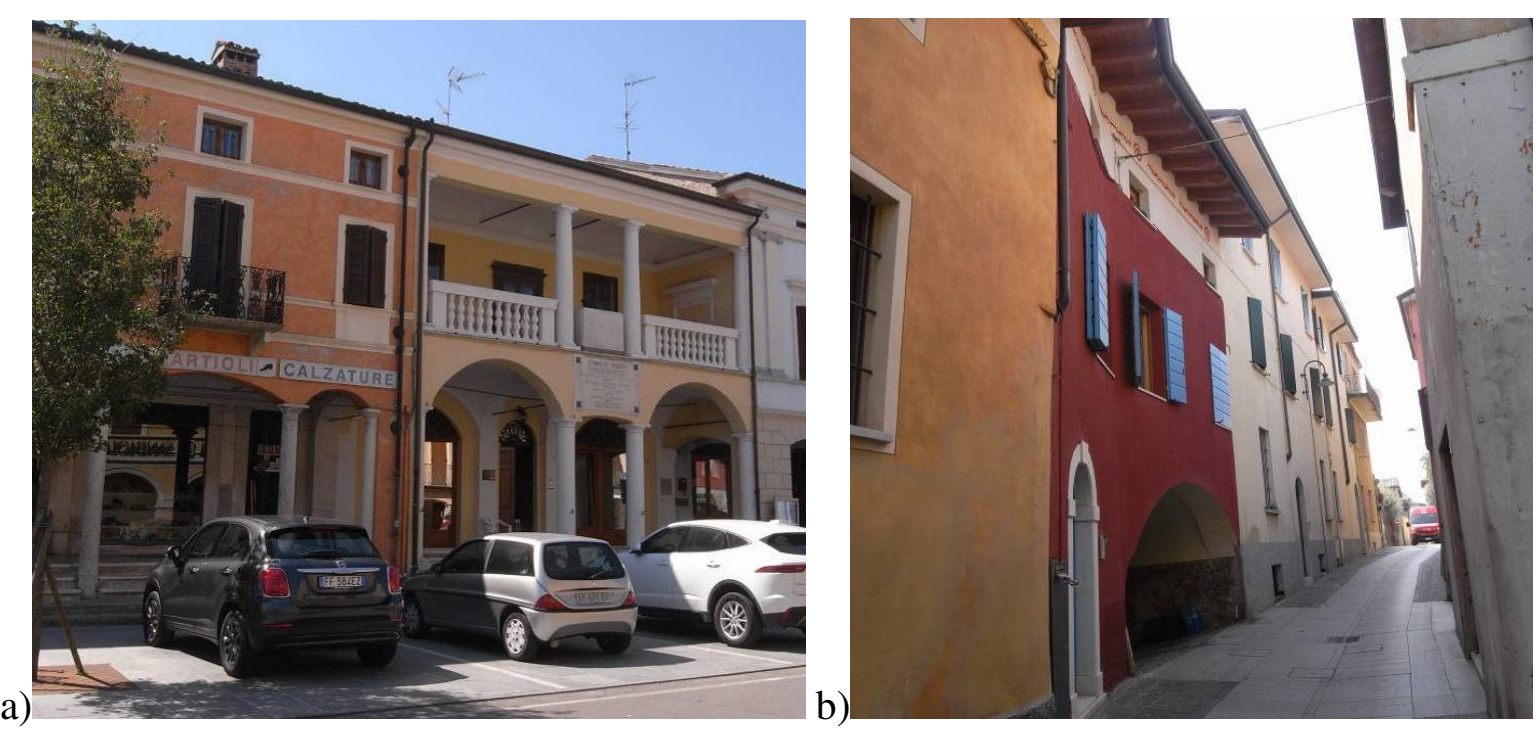

Figure 3: Fragilities in the structural units: a) porch and b) covered walkways.
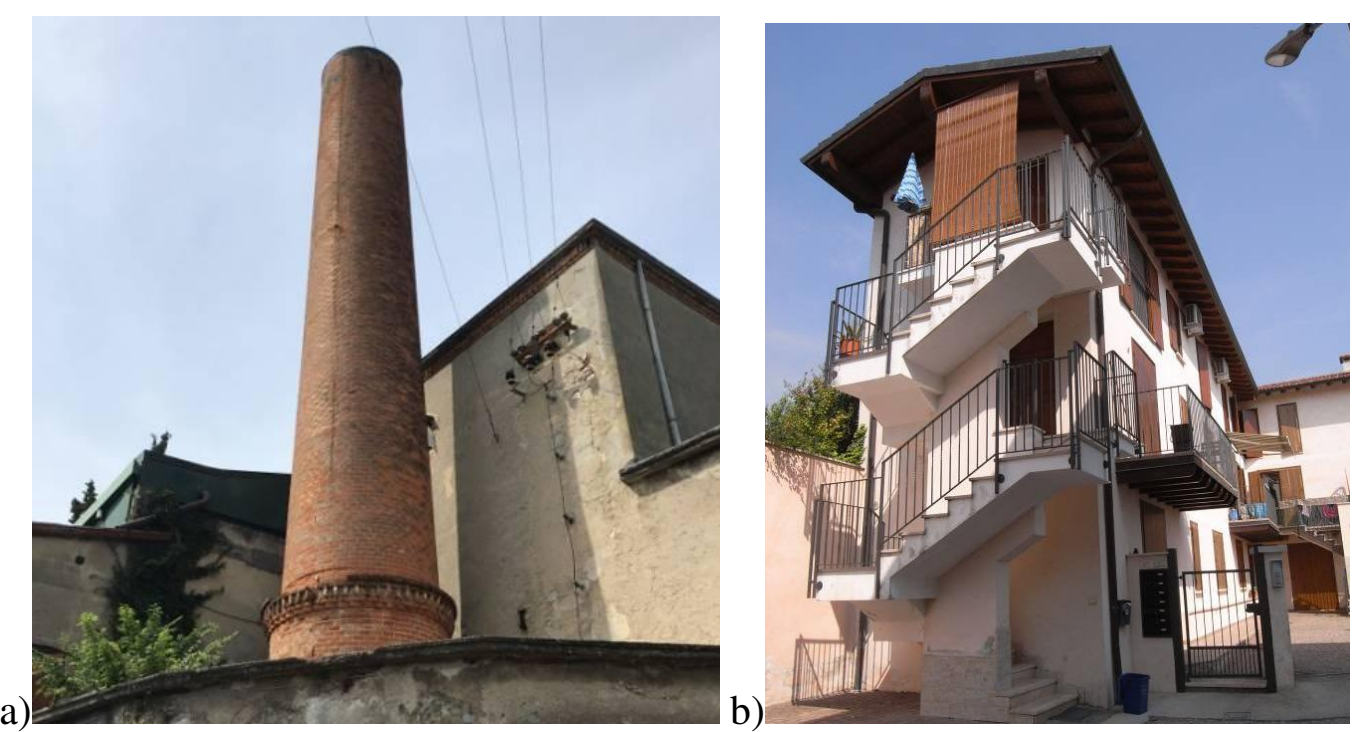

Figure 4: Fragilities in the structural units: a) slender elements; b) elements protruding on the road. 


\section{REFERENCES}

[1] Benedetti, D., Petrini, V., Sulla vulnerabilità sismica di edifici in muratura: Proposta su un metodo di valutazione. L'industria delle Costr. (1984) 149, 66-74.

[2] Giuffrè, A. Sicurezza e conservazione dei centri storici: il caso Ortigia. Laterza, (1993).

[3] Aguado, J.L.P., Ferreira, T.M., Lourenço, P.B., The Use of a Large-Scale Seismic Vulnerability Assessment Approach for Masonry FaçadeWalls as an Effective Tool for Evaluating, Managing and Mitigating Seismic Risk in Historical Centers. Int. J. Archit. Herit. (2018) 12, 1259-1275.

[4] Petrini, V., Sede indagine: regione Lombardia, provincia Brescia (1995).

[5] Carocci C. et al, Il caso di Faenza (RA)-Identificazione preliminare delle caratteristiche degli aggregati del centro storico e delle vulnerabilità osservate, (2011).

[6] Carocci C. et al, Piano di Ricostruzione del centro storico di Fossa (AQ) (2012).

[7] Rondelet, J. Traité théorique et pratique de l'art de bâtir. Parigi, Francia, 1802-1817, in : Tocci, C., Masiani, R., Lagomarsino, S., Cocina, S., Carocci, C. F., Sicurezza e conservazione degli edifici storici monumentali, pag. 78, ed.Gangemi Editore (2016).

[8] Vicente, R., Parodi , S., Lagomarsino, S., Varum, H., Mendes Silva, J. A. R., Seismic vulnerability and risk assessment: case study of the historic city centre of Coimbra, Portugal, Bull Earthquake Eng - (C) Springer Science+Business Media (2011).

[9] Ferreira, T.M., Maio, R., Vicente, R., Analysis of the impact of large scale seismic retrofitting strategies through the application of a vulnerability-based approach on traditional masonry buildings. Earthq. Eng. Eng. Vib. (2017) 16, 329-348.

[10] Ferreira T.M., Mendes N., Silva R., Multiscale Seismic Vulnerability Assessment and Retrofit of Existing Masonry Buildings, MDPI Journal (2019).

[11] Formisano, A., Florio, G., R. Landolfo, Mazzolani, F. M., Un metodo per la valutazione su larga scala della vulnerabilità sismica degli aggregati storici, ANIDIS. Bari, (2011).

[12] Bernardini, A., Giovinazzi S., Lagomarsino S., Parodi S. Vulnerabilità e previsione di danno a scala territoriale secondo una metodologia macrosismica coerente con la scala EMS-98. Convegno A.N.I.D.I.S. Pisa, Italia, (2007).

[13] Dolce, M., Masi, A., Marino, M., Vona, M., Earthquake damage scenarios of the building stock of Potenza (Southern Italy) including site effects. Bull. Earthq. Eng. (2003) 1, 115-140.

[14] Braga, F., Dolce, M., Liberatore, D. A statistical study on damaged buildings and an ensuing review of the MSK-76 scale. In Proceedings of the 7th European Conference on Earthquake Engineering, Athens, Greece, 20-25 September (1982) pp. 431-450.

[15] ATC-13. Earthquake Damage Estimation Data for California; Report ATC-13; Applied Technology Council: Redwood City, CA, USA, (1985).

[16] Faccioli, E., Pessina, V., Calvi G. M. and Borzi, B., A study on damage scenarios for residential buildings in Catania city, Article in Journal of Seismology (1999) 3, 327-343.

[17] L. Berto, P. Faccio, A. Saetta, D. Talledo, I. Zamboni, 2017, Valutazione di vulnerabilità sismica di edifici complessi/in aggregato: metodi di primo livello, in : Atti del XVII Convegno Nazionale ANIDIS, L'ingegneria sismica in Italia (Pistoia, 17-21 settembre 2017), Pisa University press, Pisa.

[18] PCM-DPC. Manuale compilazione scheda di $1^{\circ}$ livello di rilevamento danno, pronto intervento e agibilità per edifici ordinari nell'emergenza post-sismica (AeDES) (2014). 